\title{
La construcción de los cuatro pueblos en el pedemonte tucumano. La apuesta productiva del Operativo Independencia (Tucumán, 1975-1977)
}

\section{The building of the four towns in the foothills of Tucumán: the productive approach of Operation Independence (Tucumán, 1975-1977)}

\author{
Santiago Garaño \\ Universidad Nacional de Tres de Febrero / Universidad de Buenos Aires / \\ Consejo Nacional de Investigaciones Científicas y Técnicas
}

(Argentina)

sgarano@hotmail.com

En este trabajo analizaremos una de las últimas fases del Operativo Independencia, que consistió en la construcción de una ruta en el pedemonte que conectaba cuatro pueblos que llevaban nombres de personal militar "caído" en la llamada "lucha contra la subversión". Consideramos que será iluminador de esa doble faceta del poder represivo: violenta y disciplinante pero al mismo tiempo también productiva de relaciones sociales y de nuevas espacialidades. Desde esta perspectiva, sostendremos que el Operativo Independencia se convirtió en una manera de articular un dominio soberano y efectivo sobre un espacio donde había habido un déficit de presencia estatal y había estado marcado por una disputa por el control territorial por parte del frente de guerrilla rural. Sin embargo, antes que en las modalidades represivas que adoptó la represión en el sur tucumano durante el Operativo Independencia, en este trabajo nos centraremos en la faceta productiva que buscó crear un nuevo espacio, un nuevo "monte tucumano" y sostendremos que fue fundacional para el terrorismo de estado.

Palabras clave: Operativo Independencia - Soberanía - Terrorismo de Estado 


\begin{abstract}
In this essay we will analyse the last stages of "Operation Independence", which consisted in the building of a road that linked four towns named after military personnel killed in the so-called "fight against subversion", in the foothills of Tucumán. The case sheds some light over the twofold nature of repressive power: not only violent and disciplinary but also productive of new social relationships and new spatial changes in the area of the Tucuman hills. From this perspective, we argue that Operation Independence became a way to articulate an effective and sovereign domain over an area that lacked state presence, signed by a dispute with rural guerrillas over land control. However, this article does not focus on the forms of repression used in the south of Tucuman during Operation Independence. Rather, it pays particular attention to the productive aspects that aimed to create a new order in the Tucuman hills, which had paramount importance for state terrorism.
\end{abstract}

Key Words: Operation Independence - Sovereignty - State Terrorism

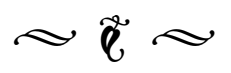

\section{Introducción}

Luego de avanzadas represivas previas, el 9 de febrero de 1975 las Fuerzas Armadas Argentinas desplegaron un vasto operativo represivo para destruir un frente rural creado por el Partido Revolucionario de los Trabajadores-Ejército Revolucionario del Pueblo (PRT-ERP): la llamada Compañía de Monte "Ramón Rosa Jiménez", que había operado desde principios de 1974 en la zona boscosa del sur de la provincia de Tucumán. ${ }^{1}$

1. La creación de la llamada Compañía de Monte era un hito en la historia de esta organización revolucionaria creada en 1965. Luego del Cordobazo, revuelta popular en de mayo de 1969, el PRT había adoptado la lucha armada como estrategia para tomar el poder; en julio de 1970 había fundado el Ejército Revolucionario del Pueblo (ERP); y, casi cuatro años después, fundaba un frente de guerrilla rural. Según explicaba la prensa partidaria, con la creación de la Compañía de Monte se iniciaba "un nuevo período en la guerra revolucionaria en nuestra patria" que, hasta ese momento, se había desarrollado en las ciudades argentinas. La creación de la Compañía de Monte se vinculaba con la caracterización
Días antes, el 5 de febrero, la presidenta constitucional María Estela Martínez de Perón había ordenado, a través de un decreto, que el "Comando General del Ejército procederá a ejecutar las operaciones militares que sean necesarias a efectos de neutralizar y/o aniquilar el accionar de elementos subversivos que actúan en la provincia de Tucumán”. ${ }^{2}$

del proceso revolucionario por parte del PRT-ERP como antiimperialista, socialista e ininterrumpido (e incluía objetivos agrarios), combinando la tradición maoísta, el legado guevariano y la experiencia vietnamita Véase: Carnovale, Vera, Los combatientes. Historia del PRT-ERP. Buenos Aires: Siglo XXI, 2011. También: versión facsímil de Estrella Roja publicada como suplemento del diario Infobae, No. 25.

2. Decreto del Poder Ejecutivo Nacional No 261, fechado el 5/2/1975. Disponible en: <http://www.desaparecidos. org/nuncamas/web/document/decreto_261_75.htm> Todavía no se hablaba de Operativo Independencia, nombre que se hizo público recién en septiembre de 1975 cuando el por ese entonces flamante Comandante en Jefe del Ejército, Jorge Rafael Videla, revistó tropas acantonadas en Tucumán. El 11 de febrero, el Comandante del III Cuerpo de Ejército, general Carlos 
Esta modalidad represiva aplicada en Tucumán -ejecutada de manera directa por las FFAA- se articuló con otras prácticas y políticas de represión política que se aplicaron a nivel nacional: las amenazas, atentados y asesinatos de organizaciones paramilitares (como la llamada Triple A- Alianza Anticomunista Argentina- o el Comando Libertadores de América); la ley 20.840 de Seguridad Nacional "para la represión de la actividad terrorista y subversiva" de octubre de 1974; y la declaración del estado de sitio en noviembre de 1974; entre otras. Gracias a la aplicación de este conjunto de medidas, se fue configurando progresivamente un estado de excepción y se fundó una lógica político-represiva centrada en la eliminación del enemigo interno. ${ }^{3}$ Sin embargo, desde principios de 1975 y hasta la finalización del Operativo, a mediados de 1977, en el imaginario represivo el monte tucumano adquirió una progresiva centralidad: a partir del inicio de este operativo, las FFAA construyeron al monte tucumano como "centro" de la estrategia del poder militar, es decir, como aquel espacio donde se libraba una "batalla decisiva" contra la llamada "subversión".

Por un lado, al fundar un "teatro de operaciones" en llamada "lucha contra la subversión”, se hizo una gran puesta en escena

Delia Larroca, en rueda de prensa, anunció el inicio del “Operativo Tucumán”, utilizando el mismo nombre que había tenido el Operativo concebido por el Gral. Onganía para cerrar once de los ingenios azucareros de Tucumán. Véase: PUCCI, Roberto, Historia de la destrucción de una provincia. Tucumán 1966, Ediciones Del Pago, Buenos Aires, 2007, p. 341.

3. FRANCO, Marina, Un enemigo para la Nación. Orden interno, violencia y "subversión", 1973-1976, Fondo de Cultura Económica, Buenos Aires, 2012. de un escenario de guerra de una guerra no convencional, utilizando un conjunto de imágenes muy caras al imaginario bélico y nacionalista: la movilización de miles de soldados, convertidos en protagonistas de la lucha; la apelación a los valores morales del "sacrificio" de la vida, el "heroísmo", la "lealtad" y el "valor"; y, la continuidad entre la gesta de la "independencia" en el siglo XIX y la "lucha contra la subversión”, entre otras cuestiones. Por el otro, el Operativo Independencia representó el inicio de una nueva modalidad de represión oculta, secreta y clandestina, a cargo del Ejército Argentino. Fue en Tucumán donde se ensayó una política institucional de desaparición forzada de miles de personas y se produjo la aparición de la institución ligada con esa modalidad represiva: los centros clandestinos de detención. ${ }^{4}$

Como vemos, el Operativo Independencia se valió de una faceta secreta, oculta y negada -la represión en los centros clandestinos de detención, tortura, desaparición y muerte-; y otra que exhibía, mostraba y espectacularizaba -en los "enfrentamientos" fraguados; en la aparición de cuerpos masacrados en la vía pública o en el monte tucumano; en los grandes operativos de secuestros y detención de opositores en las grandes ciudades y en el sur tucumano, etc.-. Junto con esta faceta destructiva, el Operativo Independencia también tuvo una faceta productiva: las FFAA asumieron la tarea de disciplinar la sociedad tucumana. Ello fue así, porque la provincia de Tucumán no sólo había sido el espacio donde se había asentado un frente de guerrilla rural;

4. COMISION BICAMERAL DE LA PROVINCIA DE TUCUMÁN, Informe de la Comisión Bicameral Investigadora de las violaciones a los Derechos Humanos en la Provincia de Tucumán, Universidad Nacional de Tucumán, San Miguel de Tucumán, 1991. 
desde el cierre de once ingenios azucareros en 1966, se había convertido en un espacio de fuerte conflictividad política y sindical y de alta movilización política. ${ }^{5}$

En trabajos anteriores, distintos investigadores han destacado la relevancia que este Operativo Independencia tuvo en la configuración de la modalidad represiva que se extendería a todo el país luego del golpe de estado del 24 de marzo de 1976. Pilar Calveiro sostuvo que este Operativo representó el inicio de una política institucional de desaparición forzada de personas, y que contó con el silencio y el consentimiento del gobierno peronista, de la oposición radical y de amplios sectores de la sociedad. ${ }^{6}$ A su vez, luego del 24 de marzo de 1976, en términos de la autora, esta modalidad de represión se convertiría en la tecnología por excelencia del poder. En la misma línea, Marina Franco ha sostenido que la represión clandestina implementada en Tucumán fue el "laboratorio" de aquello que la dictadura sistematizó un año después a escala nacional. ${ }^{7}$ Por su parte, Roberto Pucci denunció el carácter fraudulento del "mito de la guerra" en el "teatro de operaciones" del Operativo Independencia, construido gracias a la manipulación informativa y la censura sobre la prensa local y nacional, que ocultaba el "plan de exterminio sistemático" aplicado en la provincia de Tucumán, de carácter ilegal y clandestino, precursor del "terrorismo de estado". ${ }^{8}$

5. Véase PUCCI, Roberto, Historia de la destrucción de una provincia..., Op. Cit.

6. CALVEIRO, Pilar, Poder y desaparición. Los campos de concentración en Argentina, Colihue, Buenos Aires, 1998, pp. 26-27.

7. FRANCO, Marina, Un enemigo para la Nación..., Op. Cit.

8. PUCCI, Roberto, Historia de la destrucción de una
En este trabajo, analizaremos un aspecto poco explorado de las últimas fases del Operativo Independencia, que consistió en la construcción de una ruta en el pedemonte que conectaba cuatro pueblos que llevaban nombres de personal militar "caído" en la llamada "lucha contra la subversión". Consideramos que será iluminador de esa doble faceta del poder represivo: violenta y disciplinante pero al mismo tiempo también productiva de relaciones sociales y de nuevas espacialidades. Desde esta perspectiva, sostendremos que el Operativo Independencia se convirtió en una manera de articular un dominio soberano y efectivo sobre un espacio donde había habido un déficit de presencia estatal y había estado marcado por una disputa por el control territorial por parte del frente de guerrilla rural. En este sentido, mostraremos que las FFAA buscaron hacer una puesta en escena que permitiera reafirmar esa ficción constitutiva del Estado liberal moderno: la existencia de una única legalidad, de un único orden de derecho en el territorio estatal. ${ }^{9} \mathrm{Y}$, gracias al despliegue de ese poder militar, las autoridades parecían afirmar que su control soberano sobre ese territorio -y su población- era total y absoluto. Sin embargo, antes que en las modalidades represivas que adoptó la represión en el sur tucumano, en este trabajo nos centraremos en la faceta productiva que buscó crear un espacio diferente (un nuevo "monte tucumano") $\mathrm{y}$ sostendremos que fue fundacional para el ejercicio de la represión política.

provincia..., Op. Cit.

9. ESCOLAR, Diego, "La soberanía en el campo. Poder, etnografía y secreto en los Andes Sanjuaninos", en WILDE, Guillermo y SCHAMBER, Pablo (compiladores) Historia, Poder y Discursos, Paradigma Indicial SB, Buenos Aires, 2005, p. 72. 


\section{Escenas finales del Operativo Independencia}

El 28 de diciembre de 1975, diez días después de haber asumido como Comandante de la V Brigada de Infantería, Domingo Antonio Bussi, anunció que se iniciaba nuevas operaciones en la denominada "lucha contra la subversión”. Ante una formación militar en la localidad de Santa Lucía, Bussi se dirigió a la tropa:

En vísperas de iniciar nuevas operaciones contra la Delincuencia Subversiva en derrota... he sentido la necesidad de traer a ustedes... la voz del Ejército, voz que no tiene sino palabras de reconocimiento a la sacrificada, a la abnegada tarea que realizan en estos montes y cerros tucumanos tan queridos a nuestros sentimientos argentinos. Sólo quien haya vivido... la experiencia personal de haber transitado por estos lugares puede dimensionar en su verdadero valor el sacrificio, el esfuerzo y -por qué no decirlo- el patriotismo de que hay que hacer gala para superar a la naturaleza que a la par de hermosa se muestra inhóspita. Pero aquí, hoy el Ejército, como ayer y como siempre... habrá de superar con creces a la naturaleza como ya venciera a la Delincuencia Subversiva. El Ejército... se siente profundamente orgulloso de sus soldados y de la ciudadanía toda que nos observa y nos alienta... para librar a la Argentina de hoy y de siempre de estos apátridas que han pretendido sentar sus dominios, nada más ni nada menos, que en la cuna de la independencia argentina. ${ }^{10}$

Ya en su asunción como Comandante de la $\mathrm{V}$ Brigada del Ejército en diciembre

10. Diario La Gaceta, 29/12/1975, tapa y p. 2 . de 1975, en reemplazo del General Acdel Vilas, había reconocido que se trataba de la "última etapa de la lucha". De todas maneras, Bussi destacaba que la "eliminación física de los últimos delincuentes subversivos que deambulan derrotados, por estos cerros y montes tucumanos, no será ni mucho menos, la solución a los graves problemas". Para Bussi, el desafío era "apurarse" a realizar la tarea en la provincia y luego lograr el "saneamiento moral $\mathrm{y}$ físico total, $\mathrm{y}$ hasta las últimas consecuencias, de la República”. ${ }^{11}$

En vísperas de cumplirse un año del inicio del Operativo Independencia, el 8 de febrero de 1976 se dio a conocer un comunicado donde se puntualizaban los "éxitos" y "logros" obtenidos en esta lucha. Entre ellos, se destacaban la "interrupción de la estrategia subversiva", las "importantes bajas al aparato paramilitar" y la destrucción del "aparato de apoyo" rural y urbano. Además, se enfatizaba que el Ejército había ganado la "adhesión" y "colaboración" de la población tucumana. Todos estos "logros" habían impedido que la guerrilla estableciera "zona dominada" en la provincia de Tucumán. ${ }^{12}$

El 24 de marzo de 1976, las FFAA derrocaron el gobierno constitucional de Isabel Martínez de Perón, iniciaron el autodenominado "Proceso de Reorganización Nacional" y nombraron a Bussi como gobernador de facto de la provincia Tucumán, sumado al poder que ya tenía al frente del Operativo y de la V Brigada de Infantería del Ejército. El golpe de estado significó la creación de un sistema nacional de desaparición forzada de personas, es decir, representó la extensión

11. Ídem, tapa.

12. La Gaceta, 09/02/1976. 
a todo el país de la modalidad de represión política de carácter clandestino, secreto e ilegal, ensayada en la provincia de Tucumán a partir del inicio del Operativo Independencia. ${ }^{13}$ Sin embargo, durante todo el año 1976, el "monte" tucumano siguió siendo construido por el poder dictatorial como aquel "teatro de operaciones" central, donde el Ejército Argentino libraba una "batalla decisiva" contra la llamada "subversión". De hecho, el 20 de junio, el comandante del III Cuerpo de Ejército, Menéndez, presidió en Famaillá, los actos de conmemoración del Día de la Bandera. En esa oportunidad, junto con Bussi, dialogaron con un periodista del diario $L a$ Gaceta, expresando la centralidad que adquiría esa provincia en el imaginario de la represión política:

Periodista: ¿Qué significado tiene que el comandante del III Cuerpo de Ejército, con una amplia zona militar del país bajo su responsabilidad, esté en Tucumán presidiendo los actos del 20 de junio?

Gral. Menéndez: Bueno, aparte de mi predilección por Tucumán, se debe a que las tropas nuestras están en campaña, ya que si bien en este momento hay combates en toda la República, es aquí donde se desarrollan los esfuerzos más serios, más permanentes, que reclaman mayor capacidad de los comandos y de las tropas y donde está sufriendo una serie de penurias y sacrificios. Mi obligación es tratar de acompañarlos, empezando por el general y terminando por el último soldado, a estos camaradas queridos que están desarrollando esa labor tan abnegada y eficaz.

Gral. Bussi: Yo quiero agregar, por si algún

13.MITTELBACH, Federico y MITTELBALCH, Jorge, Sobre áreas y tumbas. Informe sobre desaparecedores, Sudamericana, Buenos Aires, 1992. delincuente subversivo lee estas líneas, que si estos canallas creen que matándonos un General nos van a hacer desistir están muy equivocados, porque hay 40 generales, 500 coroneles y miles de soldados que va a dar su vida hasta acabar con el último de estos cobardes. Así es como la muerte de un amigo y camarada, lejos de doblegarnos, nos renueva nuestra firme decisión de no cejar hasta matar al último cobarde”. ${ }^{14}$

Asimismo, durante el año 1976, visitaron la zona de operaciones delegaciones de artistas y deportistas (como el boxeador Carlos Monzón), estudiantes secundarios y universitarios, los ministro de Educación, de Economía y de Interior, el jefe del Estado Mayor del Ejército, Roberto Viola, y el vicario castrense. En todos los casos, estas visitas fueron ampliamente difundidas en medios de prensa nacionales e internacionales y consistían en un recorrido por el "teatro de operaciones", y en conversaciones con la tropa sobre cómo era la lucha librada en el "monte" tucumano.

Estas visitas de periodistas y personalidades al monte tucumano se convirtieron en oportunidades propicias para pulir y estandarizar un relato así como hacer una puesta en escena sobre la marcha del Operativo Independencia y difundirlo en todo el país. Michel de Certeau ha planteado que todo relato es una práctica de espacio, es decir, que dichas experiencias narradas no sólo son prácticas organizadoras del espacio sino que producen geografías de acciones: "No se limitan a desplazarlas y trasladarlas al campo del lenguaje ... organizan los andares. Hacen el viaje, antes o al mismo tiempo que los pies que

14. La Gaceta, 21/6/1976, tapa. 
lo ejecutan". ${ }^{15}$ Es en este sentido, argumenta De Certeau, que los relatos efectúan un trabajo que, incesantemente, transforma los lugares en espacios -es decir, en lugares practicados, gracias a acciones, operaciones y movimientos de sujetos históricos. ${ }^{16}$

Siguiendo esta línea interpretativa, los relatos sobre el "monte" difundidos por los medios de comunicación y en las visitas por el personal militar construían un relato que hablaba de: un lugar adverso y agreste de naturaleza indómita, plagado de riesgos y peligros; los protagonistas, los soldados como representantes de una lucha que libraba todo el pueblo argentino; el enemigo, un omnipresente, móvil y peligroso "oponente", un "combatiente irregular" simultáneamente odiado y temido; un constante peligro de muerte que no sólo los aterrorizaba sino que los volvía capaces de cualquier acto. Pero, sobre todo, construían al "monte tucumano" como aquel espacio donde se libraba una "batalla central" para ratificar la soberanía estatal en un espacio que había sido puesto en peligro por la presencia "subversiva".

Es en este sentido, que consideramos que esos relatos sobre el "monte tucumano" también "fundaron" este espacio como "teatro de operaciones". Siguiendo a Michel De Certeau, los relatos ejercen un papel decisivo no sólo en materia de organización del espacio (en operaciones de delimitación y deslinde) sino también suelen tener como "función de fundación", es decir, de crear un teatro apto para ciertas acciones. ${ }^{17}$ Sin embargo,

15. DE CERTEAU, Michel, La invención de lo cotidiano. Artes de hacer, Universidad Iberoamericana, México DF, 2010, p. 128.

16. Ídem, pp. 129 y 130.

17. DE CERTEAU, Michel, La invención de lo
De Certeau aclara que esta función no es jurídica sino que se asemeja a aquella acción ritual que los romanos efectuaban antes de toda acción civil o militar, destinada a crear el campo necesario para las actividades políticas, comerciales, diplomáticas o guerreras.

Así pues, también es una repetitiorerum: a la vez una reanudación y repetición de actos fundadores originarios, una recitación y cita de las genealogías susceptibles de legitimar la nueva empresa, y una predicción y promesa de éxito al inicio de combates, contratos o conquistas. Como se trata de una repetición general antes de la representación efectiva, el rito, narración de acciones, precede a la efectuación histórica. ${ }^{18}$

Podríamos postular, tomando esta propuesta analítica que, gracias a esta operación ritual, se fundaba un espacio apto para las acciones represivas que se iban a emprender, se creaba un campo que servía de base y teatro. Para De Certeau, ése es precisamente el papel básico del relato: abrir un teatro de legitimidad para acciones efectivas y, en ese movimiento, crear un campo que autorice prácticas sociales arriesgadas y contingentes. ${ }^{19}$

Siguiendo este marco interpretativo, podemos considerar que el conjunto de relatos partidarios sobre el "monte" buscaba producir una nueva geografía contrarrevolucionaria, donde se pretendía ratificar la soberanía estatal sobre ese territorio. Al ir progresivamente puliendo un relato del Operativo Independencia como una "batalla decisiva" que se libraba en el monte tucumano contra un "combatiente irregular", se fundaba un teatro

cotidiano..., Op. Cit., p. 136.

18. Ídem, pp. 136 y 137, cursivas en el texto original.

19. Ídem, p. 137. 
apto para legitimar primero y luego extender la zona de operaciones al resto del país. Es desde esta perspectiva que consideramos que el "monte tucumano" -y sus relatos sobre su "centralidad"- se volvió fundacional para la modalidad represiva aplicada a nivel nacional.

\section{La puesta en escena de la victoria}

De todas maneras, la puesta en escena del final exitoso del Operativo Independencia se llevó a cabo el 24 de septiembre de 1976, a seis meses del golpe militar, y con motivo del aniversario de la batalla de Tucumán, Día del Ejército Argentino y de su Generala, la Virgen de la Merced. Esa fue una oportunidad elegida por las autoridades militares para escenificar la victoria contra la Compañía de Monte Ramón Rosa Jiménez, el frente rural creado por el PRT-ERP en 1974. "Este 24 de septiembre, el Ejército hará un alto en su lucha para rendir homenaje a sus héroes”, había anunciado desde Córdoba el Comandante del III Cuerpo de Ejército, Luciano Benjamín Menéndez. ${ }^{20}$ Ese día, informó Menéndez, se entregarían una serie de medallas al personal que había participado del Operativo Independencia:

... por primera vez después de 60 años el Ejército Argentino volverá a dar medallas a sus mejores soldados. ...El Ejército Argentino invicto desde su nacimiento hace 100 años... hoy se encuentra operando en todo elámbito del país contra la delincuencia subversiva y en todos los campos de la vida nacional donde la agresión extranjera así lo exige. Esta lucha ha originado situaciones las cuales unidades o subunidades en conjunto o personal en forma individual, testimoniaron fehacientemente a través

20.La Gaceta, 22/09/76, tapa. de actos heroicos la vigencia plena de las cualidades ético-militares heredadas de sus mayores y que la institución ha atesorado con celo en largos años. El Ejército rendirá homenaje a sus héroes, héroes que se han evidenciado en sus cualidades de soldados y en su disposición para el sacrificio y el combate y que están quebrando la insolencia de la delincuencia subversiva. ${ }^{21}$

En ese acto, se entregaron distintas "Medallas de Campaña" a las unidades militares dependientes de la V Brigada de Infantería y las medallas "muerto heroicamente en combate", "heroico valor en combate" y "herido en combate" a distintos oficiales, suboficiales y soldados que participaron del Operativo Independencia. Por su parte, desde la Casa de Gobierno de la Provincia de Tucumán, el presidente de facto, Jorge Rafael Videla, emitió un mensaje trasmitido a todo el país por cadena nacional de radio y televisión:

Cuando nacía la Patria y múltiples peligros acechaban su incipiente libertad, un puñado de hombres heroicos, dirigidos por Manuel Belgrano, libró en este suelo, el 24 de septiembre de 1812, una de las decisivas batallas de nuestra emancipación. Esa batalla puso de manifiesto ante el mundo una indómita voluntad nacional. Tucumán se llamó, desde entonces, la primera gran victoria de las armas nacionales. Hoy, una vez más, rendimos homenaje a los hombres que con su abnegación y valentía hicieron posibles ese triunfo y recordamos emocionadamente a aquel arquetipo de virtudes civiles y militares que fue Manuel Belgrano...

La Patria... es la misma Patria que las FFAA y de Seguridad, que son el pueblo argentino en armas, están defendiendo con su sangre y coraje. En Tucumán,

21. Ídem, tapa. 
precisamente, la subversión concentró sus máximos esfuerzos para desintegrar el territorio nacional e implantar su ley de odio y terror. Y el pueblo de la provincia, heredero de las glorias de su pasado, una vez más, ha brindado su apoyo incondicional a las FFAA, que en todo el país están logrando la victoria ya próxima. ${ }^{22}$

En este sentido, Videla sentenció: "La esperanza ha renacido en la Argentina y empezamos a construir la paz. Su corolario... será la seguridad, es decir, la fundación de un orden justo para todos, sin excepciones.... la guerrilla ha dejado de ser una alternativa en la Argentina, porque está quebrada en su capacidad operacional y aislada de la población". ${ }^{23}$

Ese 24 de septiembre, luego del acto en Plaza Belgrano donde se entregaron las "Medallas de Campaña" del Operativo Independencia, Videla y su comitiva se trasladaron en helicóptero a la zona de Caspinchango, en la zona sur de la provincia de Tucumán, donde se iba a inaugurar el pueblo "Teniente Rodolfo Berdina". Se trataba del primero de los cuatro pueblos que se iban a construir en esa zona y llevarían el nombre de oficiales, suboficiales y soldados que habían "caído" durante el Operativo Independencia: Soldado Maldonado, Capitán Cáceres y Sargento Moya. Estos cuatro pueblos iban a estar conectados por la ruta provincial 324 que, gracias a un total de 41,9 kilómetros de asfalto entre Famaillá y Arcadia, correría paralela a la ruta nacional 38 , pero internándose en la zona de pedemonte.

22. La Opinión, 25/09/76, p. 11.

23. La Gaceta, 25/09/1976, tapa.
Después de revistar las tropas formadas, un oficial leyó el decreto del gobierno de la provincia de Tucumán que impuso el nombre de "Teniente Berdina”, donde se destacaba "la necesidad de modificar el contexto geopolíticosocial de las zonas que por sus características y topografía posibilitaron el accionar subversivo". 24 Asimismo, expresaba la "importancia" que representaría la fundación de ese pueblo "al congregar" a los pobladores de un amplio sector. $^{25}$ A continuación, Menéndez y Bussi descubrieron una placa, colocada en el centro de la plaza del pueblo, que rezaba un texto que trazaba una clara continuidad entre el pasado y el presente: “Pueblo Subteniente Berdina. Iniciación de la obra con la presencia de su excelencia el Señor Presidente de la República Argentina y el Comandante General del Ejército, Teniente General Jorge Rafael Videla, en homenaje a los mártires caídos en la Lucha Contra la Subversión, al cumplirse 164 años de la batalla de Tucumán”. ${ }^{26}$ Luego, oficiales de la Fuerza de Tareas que operaban en la zona del Operativo Independencia entregaron al presidente de facto y General del III Cuerpo de Ejército "panoplias": "Consisten -relataba una crónica periodística- en un lanza-granadas de caja hueca, recibidos por el jefe del Estado, y un winchester de repetición, entregado al Comandante del III Cuerpo. Ambas tienen inscripta esta frase: 'Como expresión de fe en el triunfo final' y fueron tomadas a extremistas”. ${ }^{27}$

Después de cantar el himno nacional e izar la bandera en el mástil de la plaza del pueblo, Videla repitió frente a los soldados

24. Ídem, p. 3.

25. Ibídem.

26. Ibídem.

27. Ibídem. 
la consigna de "subordinación y valor" para "servir a la patria". Mientras las tropas se desconcentraban, Bussi le explicó a Videla las características del pueblo, mostrándole una maqueta, y destacó que ya se habían construido las canchas de fútbol y basquetbol, la plaza y veinte viviendas que formaban parte de la primera etapa. Construido en un predio de 23 hectáreas donadas por la Compañía Azucarera Ingenio San Pablo, la crónica de La Gaceta destacaba que se trataba de "un asentamiento rural similar a otros que se están levantando en Yacuchina, Colonia 5, y Los Sosa" y que contaría con la infraestructura de servicios "indispensables para la población". ${ }^{28}$ "Las casas - detalló Bussi- no serán entregadas terminadas sino con toda la estructura exterior. El resto de la vivienda será construido por sus propios dueños, con colaboración de militares y civiles. Habrá también un centro cívico, en el que se concentrarán la policía, la comuna y la iglesia". ${ }^{29}$

\section{Vidas que vale la pena recordar}

No es casual que a seis meses del inicio de la dictadura, cuando se escenificó la victoria contra la guerrilla rural tucumana, Videla y su comitiva inauguraron el pueblo "Teniente Rodolfo Berdina”, el primero de los cuatro pueblos construidos en el pedemonte tucumano que llevarían los nombres del personal militar que había "sacrificado" su vida en el Operativo Independencia. Estos cuatro pueblos, unidos por una ruta asfaltada, parecían crear un simbólico escudo que protegería al resto de la provincia de una futura amenaza "subversiva". A su vez, se trataba de una avanzada militar

28. Ibídem.

29. Ibídem. frente a "monte" tucumano, convertido -gracias a los relatos del personal militar- en ícono de una naturaleza salvaje que amenazaba el orden urbano y capitalista. En este sentido, puede ser interpretado como un acto de soberanía donde se ratificaba el dominio del Estado argentino sobre aquel espacio en el que un frente de guerrilla rural había disputado la hegemonía estatal. A su vez, estos cuatro pueblos funcionarían como "vehículos de memoria", ${ }^{30}$ en tanto cristalizaban una memoria militar victoriosa sobre lo acontecido durante el Operativo Independencia. Al inaugurarlos, las FFAA pretendían materializar e inscribir una versión oficial de ese pasado conflictivo -la del Ejército Argentino / la del Estado Nacional-, dejando una marca espacial, permanente y pública de este relato del poder militar. ${ }^{31}$ A su vez, se volvía una huella material que simbolizaba que la "derrota" contra la guerrilla rural había sido el resultado de la acción conjunta de todo el Ejército Argentino y del "sacrificio" de sus "mejores hombres".

Sin embargo, consideramos que, lejos de considerar los actos concretos de "sacrificio" como hechos únicos e irrepetibles (apelando

30. JELIN, Elizabeth, Los trabajos de la memoria, Siglo XXI, Madrid, 2002.

31. Sobre cómo las marcas territoriales, los espacios físicos y los lugares públicos son una vía privilegiada para analizar las luchas por la memoria y los sentidos sociales del pasado reciente dictatorial en el Cono Sur de América Latina, ver JELIN, Elizabeth y LANGLAND, Victoria, "Introducción: Las marcas territoriales como nexo entre el pasado y el presente", en JELIN, Elizabeth. y LANGLAND, Victoria (compiladoras), Monumentos, memoriales y marcas territoriales, Siglo XXI, Buenos Aires, 2003, p. 3. Las autoras sostienen que se tata de estudiar los procesos sociales y políticos a través de los cuales distintos actores sociales inscriben sentidos en esos espacios y, en este mismo movimiento, transforman los "espacios" en "lugares". 
a una "memoria literal"), las autoridades militares buscaban construir una "memoria ejemplar" del Operativo Independencia y multiplicarla gracias a los medios masivos de comunicación, pero también a nivel interno de las Fuerzas Armadas, de la sociedad tucumana y del resto del país, que enviaba a soldados conscriptos, que cumplían con tareas en la zona del Operativo. ${ }^{32}$ Es decir, a partir de construir un exemplum de dichos actos sacrificiales realizados en el "monte" tucumano, se buscaba alentar que el personal militar -y la sociedad argentina en su conjunto- estuvieran dispuestos a "dar su vida por la patria" en la llamada "lucha contra la subversión".

32. Sobre la distinción entre "memoria literal" y "ejemplar", véase TODOROV, Tzvetan, Los abusos de la memoria, Paidós, Buenos Aires, 2000. Todorov consideró que la exigencia de recuperar o reivindicar la memoria no dice qué uso se hará de ese pasado. En esta línea, plantea que todo pasado puede ser leído de manera "literal", como una serie de acontecimientos que no conducen más allá de ellos mismos, es decir, como una memoria sacralizada y cristalizada. Frente a esta forma de interpretar el pasado de corte intransitivo, Todorov propone una "memoria ejemplar", es decir, una memoria que recupera ese pasado -sin negar su singularidad- como una manifestación más entre otras posibles. En este sentido, cada una de esas manifestaciones es interpretada como perteneciente a una categoría más general, lo que nos permite iluminar a partir de las experiencias extraídas del pasado situaciones nuevas con agentes nuevos. Este autor considera fundamental construir un exemplum y extraer una lección de ese pasado y, de esta manera, que el recuerdo habilite la analogía y la generalización. El pasado, gracias a la memoria ejemplar, se convierte en un principio de acción para el presente y no en un mero hecho de museo. Todorov señala que un buen uso de la memoria, la "memoria ejemplar", permite utilizar el pasado con vistas al presente, aprovechar las lecciones de las injusticias sufridas para luchar contra las que se producen en el presente, separarse del yo para ir hacia el otro. En mi caso, si bien tomo la distinción entre dos formas de hacer memoria, la despojo del sentido ético que le da Todorov y considero que nos permite conceptualizar dos maneras de relacionar pasado y presente.
Según este relato oficial, el "monte tucumano" se había convertido en aquel escenario donde el pueblo argentino y sus FFAA habían realizado los máximos "sacrificios" en aras de salvaguardar una Nación amenazada. Pero, a su vez, esas víctimas (con) sagradas obligaban a sus compañeros de armas (receptores de ese don original) a estar dispuestos ellos también a dar su vida -como forma de devolver ese don original-. Y, sobre todo, a comprometerse activamente en la "lucha contra la subversión" cuyo "teatro de operaciones", a partir de marzo de 1976, se había extendido al resto del país.

Además, al haber elegido estos 4 nombres para denominar los nuevos pueblos, las FFAA hacían una puesta en escena de qué vidas consideraban que valía la pena recordar. En el libro Vidas precarias, Judith Butler sostiene que el duelo, por un lado, constituye el medio por el cual una vida se convierte en -o bien deja de ser- una vida para recordar con dolor. En este sentido, esos actos públicos establecen y producen la norma que regula qué muertes valen la pena rememorar y, en este mismo movimiento, fijan los límites sobre el tipo de pérdidas que podemos reconocer como una pérdida. ${ }^{33} \mathrm{Al}$ mismo tiempo, para esta autora, el duelo reúne y recrea a la comunidad política -en tanto revela los lazos que nos ligan a otros y que nos constituyen como sujetos-.

Judith Butler sostiene que esta norma opera junto con la prohibición del duelo público de otras muertes y que esta distribución diferencial del duelo sirve para desrrealizar los

33. BUTLER, Judith, Vidas precarias. El poder de duelo y la violencia, Paidós, Buenos Aires, 2006, p. 59. 
efectos de la violencia estatal y militar. ${ }^{34}$ Esta autora plantea que estamos constituidos por aquellas muertes que recordamos por dolor así como por las muertes que reprimimos, esas muertes anónimas y sin rostro que integran el fondo melancólico de nuestro mundo social. ${ }^{35}$ En ese sentido, como anverso de estas muertes que merecen un obituario, Judith Butler analiza las características de una forma de violencia particular, aquella que tiene como blanco "vidas irreales".

Asimismo, para Butler, en determinados contextos sociales y condiciones históricas, algunas muertes son más dolorosas que otras, mientras ciertas vidas lejos de estar protegidas son más vulnerables. Este tipo de violencia invisible y naturalizada tiene como objeto - y también condición de posibilidad- un conjunto de vidas que no son dignas de atención ni vale la pena preservar. La eliminación violenta de este tipo de vidas no deja huella debido a que no son reconocidas socialmente como pérdidas $y$, por lo tanto, no merecen un obituario ni duelo público debido a que no encajan en el marco cultural dominante de "lo humano". Existe una relación entre la violencia que les puso fin a esas vidas, la delimitación de un universo de seres reconocidos como "humanos" -y otros que no-, y la prohibición del duelo público. Parece decirnos Butler que la violencia extrema por parte del Estado -silenciosa, natural y hasta deseada- puede ejercerse legítimamente contra quienes previamente habían sido despojados de su condición de "humano" (¿de ciudadano?). Y, en esa misma operación de poder, construía una comunidad nacional con derechos diferenciales, vidas y muertes que merecen más o menos la pena, cuerpos

34. Ídem, p. 64.

35. Ídem, p. 74.

168 más protegidos y otros vulnerables frente a la violencia del Estado.

Podríamos argumentar que, al construir estos pueblos que recordaban al personal militar y a los soldados "caídos" durante el Operativo Independencia, el poder militar marcaba qué muertes y qué vidas valía la pena recordar. A su vez, frente a Berdina, Cáceres, Maldonado y Moya, se invisibilizaba no sólo al conjunto de soldados acusados de "traidores" o potenciales "infiltrados" de la guerrilla o simplemente desaparecidos por haber sido disfuncionales, molestos o conflictivos para el poder militar. Sobre todo, era una vía para ocultar otros miles y miles de argentinos eran secuestrados y desaparecidos a lo largo de todo el país y cuyas muertes eran negadas y desaparecidas por las FFAA y de Seguridad.

\section{A modo de cierre}

En septiembre de 1977, el gobierno de la provincia de Tucumán publicó un libro titulado Tucumán, Argentina. Cuna de la Independencia, Sepulcro de la subversión. ${ }^{36}$ Construido como una versión oficial, pulida y heroica del Operativo Independencia, estaba dedicada a aquellos hombres que habían "sacrificado" sus vidas en aras de la victoria en la llamada "lucha contra la subversión". Este libro enfatizaba que, a partir del inicio de 1975, se había podido poner en marcha "con aval legal, la intervención

36. El libro está dividido en tres partes, cada una de las cuales tenía un color de fondo: "Sucedió ayer en Tucumán” (una flecha de color negro para abajo e ilustrado con fotos en blanco y negro); "Ejército Argentino: principal protagonista" (con una flecha para arriba de color verde, pero fotos en blanco y negro); "Sucede hoy en Tucumán (con una flecha celeste y contornos blancos, con fotos de color ocre). 
en el proceso tucumano", la llamada "Operación Independencia", "aplastando decidida y terminantemente a los elementos espurios de la subversión terrorista". ${ }^{37}$ Luego, mostraba que "el Ejército Argentino sumó, a la responsabilidad de erradicar los focos del terrorismo enquistado en el monte tucumano, la no menos importante de reorganizar la querida provincia de TUCUMÁN...”. En este sentido, se destacaba el resto de las tareas que habían realizado para "reorganizar" la provincia de Tucumán: según este relato oficial, primero, se buscaba aniquilar toda forma de oposición, desapareciendo todo sujeto considerado molesto, incómodo o conflictivo para el poder militar. Luego, se debía emprender una empresa productiva, que alterase las relaciones sociales y produjese una sociedad tucumana ordenada, disciplinada, silenciosa y armoniosa. Ese parecía haber sido el doble objetivo del Operativo Independencia.

Contemporáneamente a este libro, Vilas escribió un "diario de guerra" donde relató su experiencia directa comandando la primera etapa del Operativo Independencia (entre febrero y diciembre de 1975) ${ }^{38}$. Redactado mientras era Segundo Comandante y jefe del Estado Mayor del V Cuerpo de Ejército y Jefe de la Subzona 51 con asiento en Bahía Blanca, en este "diario de campaña", Vilas admitía y justificaba "la implementación de

37. GOBIERNO DE LA PROVINCIA DE

TUCUMÁN, Tucumán, cuna de la independencia, sepulcro de la subversión, Poder Ejecutivo Provincia de Tucumán, San Miguel de Tucumán, 1977, pp. 2 y 3.

38. Vilas, Acdel, Tucumán: el hecho histórico. El plan táctico que posibilitó la victoria contra el Ejército Revolucionario del Pueblo (ERP) en 1975, Mimeo, 1977. Obrante en la Biblioteca Nacional. Versión digital, disponible en : <http://web.archive.org/web/20031112080748/www. nuncamas.org/investig/vilas/acdel_00.htm> los secuestros ya que: 'Si el procedimiento de detención se hubiera realizado vistiendo uniforme, entonces no había más remedio que entregarlo a la justicia para que en pocas horas saliese en libertad; pero si la operación se realizaba con oficiales vestidos de civil y en coches 'operativos', como lo ordené ni bien me di cuenta de lo que era la justicia y la partidocracia, la cosa cambiaba"' ${ }^{39}$ En contraste con el libro del gobierno tucumano, su publicación fue prohibida por la conducción de las FFAA debido a que el autor reconocía el despliegue de prácticas de represión de carácter ilegal y clandestino que sistemáticamente el gobierno de facto negaba en todos los foros nacionales e internacionales. ${ }^{40}$

De todos los argumentos sostenidos por Acdel Vilas en este manuscrito inédito, nos gustaría destacar uno que, a primera vista, parecería contradecir la centralidad que tenía el "monte" tucumano en la estrategia represiva de las Fuerzas Armadas. En este "diario de campaña", sostenía que el "verdadero meollo del problema" estaba en la ciudad de San Miguel de Tucumán y no el "monte":

¿Por qué los nombrados grupos operativos desenvolvían su acción en el ámbito de la

39. “En palabras de Vilas, 'sólo los inofensivos' llegarían ante los jueces. Según reconoce el propio Vilas, 'del 10 de febrero al 18 de diciembre de 1975, pasaron por 'La Escuelita' 1507 personas acusadas de tener vinculación estrecha con el enemigo' (1977: 11, 26 y 27 y 9)”. En CRENZEL, Emilio, "E1 Operativo Independencia en Tucumán”, en ORQUERA, Fabiola (editor) Ese ardiente Jardín de la República. Formación y desarticulación de un "campo" cultural: Tucumán, 1880-1975, Alción Editora, Córdoba, 2010, p. 386.

40. Si bien este manuscrito no fue publicado por ninguna editorial, hoy se puede consultar en algunas bibliotecas como la del Congreso Nacional, la Biblioteca Nacional y la del Centro de Estudios Legales y Sociales. 
capital, principalmente? Pues porque de las declaraciones tomadas en [el centro clandestino que funcionaba en] Famaillá llegamos a la conclusión de que la base de operaciones del ERP era la ciudad y no el monte como suponían algunos. Sin la cobertura que les daba Tucumán, los campamentos situados en plena selva no hubiesen resistido treinta días de lucha, pero el foco de la infección marxista estaba en San Miguel y resultaba un esfuerzo baldío creer lo contrario. De aquí que mi determinación de incluir en la zona de operaciones a la capital haya sido correcta. ${ }^{41}$

En función de esta apreciación de Vilas, nos preguntamos: ¿por qué el "monte tucumano" fue construido como el «centro» de la estrategia represiva si, para el Comandante de la V Brigada, el "foco de infección marxista" estaba en la ciudad de San Miguel de Tucumán? Como hemos planteado en trabajos anteriores, las Fuerzas Armadas desplegaron una serie de puestas en escenas de una guerra no convencional y de un conjunto de imágenes muy caras al imaginario bélico y nacionalista. Su potencia radicaba en la "fundación" de un "teatro" apto para las acciones militares, gracias a un triple mecanismo: una repetición de actos originarios; una apelación a genealogías susceptibles de legitimar la nueva empresa; y una promesa de éxito al inicio de la acción militar. Gracias a esa operación «fundacional», se construía la legitimidad del Operativo, trazando una directa continuidad de la "lucha" del presente con el pasado nacional; se cimentaba la cohesión del grupo y las jerarquías internas; y se inculcaba determinados valores morales -de "sacrificio", "compañerismo" y "heroísmo"-. Ello así, debido a que la provincia

41. VILAS, Acdel, Tucumán: el hecho histórico. El plan táctico que posibilitó la victoria contra el Ejército Revolucionario del Pueblo (ERP) en 1975,mimeo, 1977. de Tucumán adquiría un fuerte contenido simbólico: el Ejército Argentino reconocía que era un espacio paradigmático destinado a dramatizar el "sepulcro" de la "subversión". Asimismo, para las FFAA en el "monte tucumano" se volvía el "teatro" donde se habían realizado "sacrificios" que se volvieron "fundacionales" en la llamada "lucha contra la subversión". Luego del golpe de estado de 1976, estos "sacrificios" tendrían que funcionar obligando a otros oficiales, suboficiales y soldados a estar dispuestos no sólo a comprometerse activamente con esta lucha sino a matar y morir en los nuevos "teatros de operaciones" a lo largo de todo el país.

\author{
Recibido: 08/01/2015 \\ Aceptado: 23/06/2015 \\ Publicado: 31/07/2015
}

